\title{
КОМПЛЕКСНЫЙ АНАЛИЗ ТУРИСТИЧЕСКИХ УСЛУГ В АЗЕРБАЙДЖАНЕ И ЕГО ИННОВАЦИОННОЕ РАЗВИТИЕ
}

\author{
Абасова Самира Гусейн кызы, д.э.н. МОАН, дои. \\ Азербайджан, г. Баку, Институт Экономики НАН Азербайджана
}

DOI: https://doi.org/10.31435/rsglobal_ws/30082018/6056

\section{ARTICLE INFO}

Received: 04 July 2018

Accepted: 13 August 2018

Published: 30 August 2018

\section{KEYWORDS}

tourism in Azerbaijan,

SWOT analysis of tourism in

Azerbaijan,

strategies of tourism development in

Azerbaijan,

marketing strategies for innovation

development of tourism in

Azerbaijan. \begin{abstract}
This paper considers some problems in tourism sector of Azerbaijan. Author has analysed the statistical dates of tourism in Azerbaijan, investigated problems by Porterls method and SWOT analysis. Author suggests to use marketing strategies for innovation development of tourism sector of Azerbaijan.
\end{abstract}

Citation: Абасова Самира Гусейн кызы. (2018) Kompleksnii Analiz Turisticheskih Uslug v Azerbaidjane i ego Innovacionnoe Razvitie. World Science. 8(36), Vol.1. doi: 10.31435/rsglobal_ws/30082018/6056

Copyright: (C) 2018 Абасова Самира Гусейн кызы. This is an open-access article distributed under the terms of the Creative Commons Attribution License (CC BY). The use, distribution or reproduction in other forums is permitted, provided the original author(s) or licensor are credited and that the original publication in this journal is cited, in accordance with accepted academic practice. No use, distribution or reproduction is permitted which does not comply with these terms.

Введение. Туризм является не только одним из прибыльных отраслей экономики, но он отличается от других сфер деятельности тем, что оборотные средства быстро окупаются, создавая новый задел для его инновационного развития. В связи с этим данная статья не только анализирует статические данные туристической отрасли Азербайджана, но также оценивает перспективы его дальнейшего развития.

1. Анализ деятельности туристической отрасли в Азербайджане

За последние 8 лет туризм в Азербайджане стал развиваться быстрыми темпами. Особенно это стало заметно, после проведения ряд спортивных соревнований международного масштаба, к которым относятся Европейские олимпийские игры, проведение Формулы 1 , гимнастические и шахматные соревнования и т.д.

В таблице 1. даны технико-экономические показатели развивающейся туристической отрасли Азербайджана. Как видно из таблицы за 2010-2016 гг. если количество туристических агенств возросло почти в 2 раза, то работающих в сфере туризма увеличилось в несколько тысяч раз. К ним относятся переводчики, временный обслуживающий персонал как в гостиницах, в метах общего питания, так и в сфере транспортного обеспечения [5].

За истекший период прибыль от туризма возрос почти в 2,5 раза, а расходы увеличились только в 2 раза. В связи с наплывом иностранцев увеличились их поездки не только в столицу, но и в периферии. Это связано не только тем фактом, что в Азербайджане в основном развивался экотуризм и охотничий туризм [6].

Все больше внимание уделяется на развитие кулинарного туризма. Исторический и религиозный туризм также являются одним из основных направлений этой отрасли. В последнее время туристические агентства все больше услуг предлагают в сфере лечения - в 
Азербайджане немало природных гейзеров, грязевых вулканов, целебных источников, соляных пещер для поправки здоровья. Здесь реконструированы советские здравницы, построены современные лечебницы, которые оборудованы новейшими медицинскими приборами.

Как видно из таблицы 2. за последние 5 лет количество взрослых и детских санаторий уменьшилось - закрылись из-за негодности здания. Очень заметно и уменьшение койка мест в этих учреждениях - за годы самостоятельности многие учреждения не получали достаточных дотаций на содержание зданий, за обновление фондов, что привело к их разрушению [7].

Таблица 1. Динамика основных технико-экономических показателей туризма в Азербайджане

\begin{tabular}{|c|c|c|c|c|c|}
\hline Показатели & 2010 & 2014 & 2015 & 2016 & $\begin{array}{l}\text { В } 2016 \text { по } \\
\text { отн. } 2010, \%\end{array}$ \\
\hline Количество туристических агентств & 126 & 218 & 243 & 272 & 215,8 \\
\hline $\begin{array}{l}\text { Численность работников (включая } \\
\text { совместителей)), чел. }\end{array}$ & 1418 & 1794 & 1586 & 1838 & 1328,5 \\
\hline $\begin{array}{l}\text { В т.ч.: } \\
\text { Занятые в сфере туризма, чел. }\end{array}$ & 1159 & 1567 & 1308 & 1472 & 127,0 \\
\hline Полученная прибыль, тыс. манат & 19065,3 & 31107,1 & 36482,2 & 36758,3 & 193,8 \\
\hline В т.ч.: От туризма & 14755,5 & 26031,0 & 35079,6 & 34834,2 & 236,1 \\
\hline $\begin{array}{l}\text { Расходы на производство } \\
\text { продукции и услуг, тыс. манат }\end{array}$ & 17811,3 & 27018,1 & 30811,6 & 29101,8 & 163,4 \\
\hline В.т.ч.: От туризма & 13805,7 & 25708,60 & 29480,0 & 27308,5 & 197,8 \\
\hline Количество путевок, ед. & 34121 & 66233 & 44615 & 36978 & 108,4 \\
\hline $\begin{array}{l}\text { Из них: } \\
\text { Внутри страны для граждан } \\
\text { Азербайджана, ед. }\end{array}$ & 3385 & 6990 & 4695 & 5842 & 172,6 \\
\hline $\begin{array}{l}\text { Зарубежные поездки для граждан } \\
\text { страны, ед. }\end{array}$ & 27030 & 54900 & 38002 & 24368 & 90,2 \\
\hline Иностранцам внутри страны, ед. & 3706 & 4343 & 1918 & 6768 & 182,6 \\
\hline Стоимость путевок, тыс. манат & 25848,7 & 44820,3 & 33474,7 & 33466,5 & 129,5 \\
\hline $\begin{array}{l}\text { В т.ч.: } \\
\text { для азербайджанцев внутри страны, } \\
\text { тыс. манат }\end{array}$ & 1708,4 & 2764,0 & 4039,7 & 3932,2 & 230,2 \\
\hline $\begin{array}{l}\text { Для азербайджанцев за пределами } \\
\text { страны, тыс.манат }\end{array}$ & 19750,2 & 39708,5 & 28622,7 & 23893,5 & 120,9 \\
\hline $\begin{array}{l}\text { Иностранцам для поездки по } \\
\text { Азербайжану, тыс.манат }\end{array}$ & 4390,2 & 2347,8 & 812,3 & 5640,9 & 128,5 \\
\hline $\begin{array}{l}\text { Численность принятых и } \\
\text { отправленных туристов, чел. }\end{array}$ & 69923 & 92305 & 61965 & 53999 & 77,2 \\
\hline
\end{tabular}

Источник: [6] https://www.stat.gov.az/source/tourism

Но отрадным фактом является увеличение спортивных сооружений и олимпийских комплексов. Как видно из таблицы 3. Количество спортивных зданий и сооружений каждым годом растет. С 2001 г. количество спортивных сооружений увеличилось на 41,8\%, плавательных бассейнов - на 205,4\%. Увеличилось также численность людей, занимающихся активной физической подготовкой примерно в 5 раз [7].

Как видно из таблицы 3. увеличение количества спортивных сооружений говорит о спортивной активности не только спортсменов, но и населения, что в дальнейшем поспособствует общему оздоровлению населения республики.

Необходимо отметить тот факт, что туристические агентства в последние годы активно сотрудничают со спортсменами не только среди граждан республики, но и зарубежья. Участились подготовки спортсменов из арабских государств - этому способствует не только современные спортивные сооружения, но и благоприятные природные условия страны. 
Таблица 2. Технико-экономические показатели санаторий и туристических баз в Азербайджане

\begin{tabular}{|l|c|c|c|c|}
\hline \multicolumn{1}{|c|}{ Показатели } & 2012 & 2014 & 2016 & 2017 \\
\hline Количество санаторий, лечебниц, баз отдыха, всего & 73 & 72 & 68 & 65 \\
\hline В т.ч. количество койка мест & 11168 & 10419 & 9894 & 9570 \\
\hline Количество санаторий & 29 & 30 & 28 & 28 \\
\hline В т.ч.койка мест & 5695 & 5765 & 5552 & 5643 \\
\hline Количество детских санаторий & 14 & 14 & 13 & 13 \\
\hline Количество койка мест & 1050 & 1030 & 910 & 1001 \\
\hline Количество санаторий-профилакторий & 3 & 2 & 2 & 2 \\
\hline В том числе количество койка мест & 51 & 64 & 64 & 64 \\
\hline Количество центров реабилитации & 4 & 5 & 5 & 4 \\
\hline Количество мест & 695 & 707 & 760 & 562 \\
\hline Количество домов отдыха, пансионатов, профилакторий & 20 & 19 & 18 & 16 \\
\hline Количество мест & 2438 & 2146 & 1898 & 1681 \\
\hline Количество баз отдыха и др. учреждений & 17 & 16 & 15 & 15 \\
\hline Количество мест & 2289 & 1737 & 1620 & 1620 \\
\hline
\end{tabular}

Источник: [7] https://www.stat.gov.az/source/healthcare/

Таблица 3. Показатели спортивных объектов в Азербайджане

\begin{tabular}{|l|r|r|r|r|}
\hline \multicolumn{1}{|c|}{ Показатели } & \multicolumn{1}{c|}{2001} & \multicolumn{1}{c|}{2010} & \multicolumn{1}{c|}{2015} & \multicolumn{1}{c|}{2017} \\
\hline Спортивные сооружения - всего & 7908 & 9623 & 10798 & 11215 \\
\hline Из них: & & & & \\
\hline Спортивные дворцы & $\ldots$ & 3 & 3 & 3 \\
\hline Олимпийские комплексы & $\ldots$ & 24 & 39 & 39 \\
\hline Стадионы, вмещающие более 1,5 тыс. чел & 75 & 56 & 74 & 75 \\
\hline Стадионы, вмещающие менее 1,5 тыс. чел & $\ldots$ & 83 & 122 & 118 \\
\hline Комплексны спортивные сооружения & 399 & 233 & 180 & 188 \\
\hline Плавательные бассейны & 37 & 53 & 84 & 113 \\
\hline Стрельбища & 314 & 240 & 176 & 170 \\
\hline $\begin{array}{l}\text { Численность, занимающихся физической культурой, } \\
\text { тыс.чел. }\end{array}$ & 355,2 & 1617,40 & 1723,8 & 1755,4 \\
\hline
\end{tabular}

Источник: [7] https://www.stat.gov.az/source/healthcare/

Развивая новые виды и направления для привлечения иностранных туристов в Азербайджан многие предприятия туризма обращаются $\kappa$ нововведениям в области информационных технологий, банковского обслуживания и on-line сервиса. Суть в разработке стратегии развития, а также сосредоточения необходимых услуг как в самом туристическом агентстве, так и вокруг определенных туристических направлений. Например, это фокусировка туристической привлекательности со столицы в периферию - г. Габала, где создан международный аэропорт, не раз проходит музыкальный фестиваль, фестиваль варенья, там же сосредоточены филиалы крупных банков, отелей международного 5зведночного уровня, несколько крупных развлекательных центров, канатная дорога, услуги беспроводной интернет [2]. 
Таблица 4. Технико-экономические данные в отраслях, сопредельных туризму

\begin{tabular}{|c|c|c|c|c|c|}
\hline Показатели & 2013 & 2014 & 2015 & 2016 & $\begin{array}{l}\text { В } 2016 \text { по } \\
\text { отн. } \\
2013 \text { г., \% }\end{array}$ \\
\hline $\begin{array}{l}\text { Численность, работающих в } \\
\text { сопредельных к туризму } \\
\text { отраслях, чел. }\end{array}$ & 40892 & 41886 & 49449 & 43477 & 106,3 \\
\hline $\begin{array}{l}\text { Объем добавленной стоимости, } \\
\text { полученных в сопредельных к } \\
\text { туризму отраслях, млн. манат }\end{array}$ & 2080,20 & 2404,20 & 2437,3 & 2594,7 & 124,7 \\
\hline $\begin{array}{l}\text { Уд. Вес дополнительной } \\
\text { стоимости в общем ВВП, } \\
\text { полученных в сопредельных к } \\
\text { туризму отраслях, \% }\end{array}$ & 3,6 & 4,1 & 4,5 & 4,3 & - \\
\hline $\begin{array}{l}\text { Объем инвестиций, вложенных } \\
\text { сопредельных к туризму } \\
\text { отраслях, тыс. манат }\end{array}$ & 1,4 & 2,2 & 1,0 & 0,4 & 72,0 \\
\hline
\end{tabular}

Источник: [6] https://www.stat.gov.az/source/tourism

Как видно из таблицы 4. хоть медленными темпами, но туризм также способствует развитию других отраслей экономики Азербайджана - к ним относятся не только проживание и общественное питание, а также транспортное обслуживание, но организация производство шелка и сбыт традиционных изделий из него (платки, шарфы, косынки), ковроткачество и реализация сувенирных миниатюрных ковров, изготовление национальных кондитерских изделий (шекербура, бадамбура, гогал, пахлава, халва и т.д.), транспортное и банковское обслуживание и др.

Но недостаточность инвестиций еще раз указывает на тот факт, что туристическая отрасль Азербайджана еще в начале пути своего развития. Необходимо провести более тщательные оценки туристической деятельности, подключить серьезные маркетинговые исследования, провести расчет себестоимости каждой услуги и найти способы уменьшения их.

2. Экспертный SWOT-анализ туристических услуг в Азербайджане.

С целью определения основных направлений распространения туристских услуг и их дальнейшего распространения в Азербайджане. В сложившейся ситуации для определения используем методику SWOT-анализа. Применение этой методики к оценкам рекреационных ресурсов определяет вывод о необходимости конкурентной стратегии распространения туристских услуг.

Наверняка, многие обратят внимание на и центральное географическое положение Азербайджана, на пассажиропотоки как по направлению Север-Юг, также и по направлению ЗападВосток и обратно, значительный и разнообразный природно-ресурсный потенциал (и прибрежные зоны Каспия с пляжами белыми, желтыми, также черными песками), наличие нетронутых природных ландшафтов, целой сети особо охраняемых природных территорий (9 климатических зон), наличие богатого историко-культурного наследия (Азербайджан - территория 3 мировых религий и Зароастризма), гостеприимность народов, заселявшие эти земли. Все перечисленные аспекты только усиливают привлекательность туристических туров в эту страну. Но, некоторые туристические услуги у нас неразвиты в регионах. К ним относятся:

$>$ Незнание языков - в регионах страны не все умеют говорить на русском, тем более на английском и на других иностранных языках;

$>$ Недостаточное качественное обслуживание персонала - многие ничего не знают о стране, о ее культуре и о кодексе поведения, из которого приехал гость и соответственно некоторые местные обычаи могут шокировать иностранца (близко общение с гостем, манера разговора и позирование);

$>$ Отсутствие вегетарианской и веганской кухни;

$>$ отсутствие современных систем канализации, сбора и утилизации бытовых отходов в регионах. 
Таблица 5. SWOT анализ туристических услуг в Азербайджане

\begin{tabular}{|c|c|}
\hline S (сильные положительные стороны) & W (слабые / негативные стороны) \\
\hline $\begin{array}{l}\text { развитые экономические и культурные } \\
\text { международные связи, значительное } \\
\text { количество реализуемых международных } \\
\text { проектов и программ, в том числе в } \\
\text { области туризма; } \\
\text { > наличие программы развития туризма в } \\
\text { Азербайджане и ее успешная реализация. }\end{array}$ & $\begin{array}{l}\text { нехватка финансовых инвестиционных } \\
\text { ресурсов; } \\
\text { н недостаточно развитая туристско- } \\
\text { рекреационная инфраструктура (в том числе } \\
\text { низкий уровень обслуживания туристов); } \\
\text { > неудовлетворительное состояние } \\
\text { значительной части объектов историко- } \\
\text { культурного наследия (многие объекты не } \\
\text { могут быть включены в систему } \\
\text { экскурсионного показа и оn-line просмотра в } \\
\text { рекламе); } \\
>\text { недостаток турпродуктов, отвечающих } \\
\text { мировым стандартам; } \\
>\text { недостаточность и труднодоступность } \\
\text { объективной аналитической информации в } \\
\text { области туризма; } \\
>\text { широкое распространение использование } \\
\text { приграничного туризма. }\end{array}$ \\
\hline О (возможности /перспективы) & Т (угрозы) \\
\hline $\begin{array}{l}\text { использование возможностей для } \\
\text { развития экологического, спортивного, } \\
\text { водного, а также культурного и делового } \\
\text { туризма; } \\
\text { о возможность организации программ } \\
\text { обучения специалистов в области туризма } \\
\text { на базе ведущих учебных заведений } \\
\text { Азербайджана; } \\
>\text { осуществление государственной } \\
\text { подержки и информационной } \\
\text { доступности туризма Азербайджана; } \\
\text { развитие туристской инфраструктуры за } \\
\text { счёт реализации международных проектов } \\
\text { и привлечения инвестиций в туристскую } \\
\text { сферу. }\end{array}$ & $\begin{array}{l}>\text { несовершенство нормативно-правовой базы } \\
\text { туризма; } \\
\text { низкий платёжеспособный спрос населения } \\
\text { на услуги туризма, даже внутреннего туризма; } \\
>\text { ужесточение конкурентной борьбы за } \\
\text { туристские потоки в регионе среди турагентств; } \\
>\text { угрожающий рост туристов из арабских } \\
\text { стран. }\end{array}$ \\
\hline
\end{tabular}

Источник: составлена автором на основе данных [1-2]

Совершенствование и эффективное использование туристических ресурсов непосредственно связано с повышением конкурентоспособности туристической индустрии республики. Каждая составляющая туристических услуг должна быть разработана с учетом специфических предложений. Метод портфельного анализа с соответствующими матрицами базовых стратегий, а также изучение их влияний на различные события внешней и внутренней среды раскрывает детерминант конкурентных преимуществ.

Таблица 6. «Конкурентный ромб» Портера

\begin{tabular}{|c|c|}
\hline Факторные условия & Кластеры составляющих туризма \\
\hline $\begin{array}{ll}> & \text { Природные условия; } \\
\text { Людские ресурсы; } \\
\text { Инфраструктура, в т. ч. качество жизни; } \\
\text { Инновации и отношение к ним; } \\
\text { Капитал. }\end{array}$ & $\begin{array}{l}>\text { Гостиничное хозяйство; } \\
>\quad \text { Система питания; } \\
>\quad \text { Транспортное обслуживание; } \\
\text { Оборудование и т.д. }\end{array}$ \\
\hline Условия внутреннего спроса & Стратегия и структура туризма \\
\hline $\begin{array}{ll}> & \text { Качество и уровень спроса; } \\
>\quad \text { Соответствие мировым тенденциям; } \\
\quad \text { Развитие объёма спроса и т.д. }\end{array}$ & $\begin{array}{l}>\text { Внутриотраслевая конкуренция; } \\
\text { Ц } \quad \text { Цели, стратегия, способы организации, } \\
\text { менеджмент и т.д. }\end{array}$ \\
\hline
\end{tabular}


Как видно из ромба Портера [2-4] все составляющие, главным образом связаны с вопросами финансирования. Улучшение качеств услуг связано с подготовкой и переподготовкой кадров, обучениям инновационному мышлению и стратегическому поведению, а это в свою очередь - с привлечение высококвалифицированных специалистов, для приглашения которых необходимо потратиться. Транспортное обслуживание в свою очередь требует не только наличие комфортабельных транспортных средств и квалифицированного водителя, также наличие хороших автомобильных дорог и инноваций, что возможно лишь с помощью финансирования.

Следовательно, решение этих и смежных проблем возможно при наличии финансов или его можно решать с помощью привлечения инвестиций в сферу туризма. К трудностям также относятся следующие негативные факторы:

$>$ несовершенство законодательной системы, особенно в налоговой сфере;

> недостаточная развитость банковско-кредитной системы.

Изучив расположение элементов этой матрицы, и применив полученные данные, автор пришел к выводу, что конкурентное развитие туризма в Азербайджане, будет осуществляться на базе изменения негативных факторов, активного внедрения инноваций как в подборе персонала и его обучения, так и в предоставления туристических услуг [2]. Характерно, что вышеперечисленные оставляющие невозможно достичь без решения вопросов финансирования и активного вовлечения инвестиций. А в дальнейшем успешная реализация необходимых решений привлечет за собой богатство наций.

3. Инновационное развитие туристических услуг в Азербайджане.

Формирование на территории Азербайджана современной конкурентоспособной туристической отрасли первоочередная задача инновационного и стратегического развития республики. Туризм, как и другие отрасли национальной экономики, в первую очередь, нуждается в инновациях, особенно в совершенствующем маркетинге туристических услуг и рекламной деятельности, во-вторых, инновационное развитие туристической отрасли невозможно отделить от правильного выбора стратегии маркетинга и развития [1].

В таблице 7. рассмотрены осязаемые и неосязаемые туристические услуги. Как видно из таблицы 7. свойства покупательной способности делятся на осязаемые и неосязаемые услуги, и соответственно, туристические услуги также бывают различными по своим свойствам [2].

Туристские услуги как разновидность продукта можно разделить на:

$>$ относящиеся к физическим продуктам (обеспечение гостиницей, организация питания и т.д.);

$>$ связанные с применением продукта (активные походы, ночевка под открытым небом, зажигание костров и т.д.);

> чистые услуги (экскурсии, продажа турпакетов, продажа авиабилетов, бронирование, страхование и т.д.).

Таблица 7. Характеристика туристических услуг Азербайджана [2, с.121]

\begin{tabular}{|c|c|c|c|}
\hline \multicolumn{2}{|r|}{, } & $\begin{array}{c}\text { Спрос населения } \\
\text { на виды услуг }\end{array}$ & $\begin{array}{c}\text { Предлагаемые туристические } \\
\text { услуги }\end{array}$ \\
\hline \multirow[t]{2}{*}{$\begin{array}{l}\text { Природа } \\
\text { действий по } \\
\text { туристически } \\
\text { м услугам }\end{array}$} & $\begin{array}{l}\text { Осязаемые } \\
\text { действия }\end{array}$ & $\begin{array}{l}\text { - туризм; } \\
\text { - здравоохранение; } \\
\text { - центры здоровья; } \\
\text { - пассажирские перевозки; } \\
\text { - обеспечение гостиницей; } \\
\text { - обеспечение питанием } \\
\text { (рестораны, кафе, бистро); } \\
\text { - парикмахерские услуги. }\end{array}$ & $\begin{array}{l}\text { - перевозки; } \\
\text {-реабилитация; } \\
\text {-приготовление еды и } \\
\text { обслуживание; } \\
\text {-предоставление номеров в } \\
\text { гостиницах; } \\
\text { - ремонт и установка } \\
\text { оборудования; } \\
\text { - уборка территорий; } \\
\text { - чистка и стирка; } \\
\text { - охрана; } \\
\text { - помощь. }\end{array}$ \\
\hline & $\begin{array}{l}\text { Неосязаемые } \\
\text { действия }\end{array}$ & $\begin{array}{l}\text { - наблюдение, диалог, селфи и } \\
\text { фотосессии, а также их } \\
\text { обработка; } \\
\text { - посещение музеев и } \\
\text { достопримечательностей; } \\
\text {-безналичный расчет при } \\
\text { покупке товаров и услуг; } \\
\text {-безопасность. }\end{array}$ & $\begin{array}{l}\text {-телевидение; } \\
\text {-радиовещание } \\
\text { - рекламная деятельность; } \\
\text {-информационные технологии; } \\
\text { - банки и расчётные } \\
\text { операции; } \\
\text { - юридические консультации; } \\
\text { - страхование. }\end{array}$ \\
\hline
\end{tabular}


Потенциальные потребители делятся на несколько групп:

1. новаторы $-2,5 \%$. Их характеризует склонность к риску, эксперименту, они социально динамичны, коммуникабельны, космополитичны;

2. активные лица - 13,5\%. Им нравится руководить, они любят престиж, формируют мнение;

3. быстро адаптирующееся большинство - 34\%. Эти лица занимают определённое социальное положение, коммуникабельны, внимательны к информации;

4. медленно признающее большинство - 34\%. Это лица более низкого социального уровня, старшего и среднего возраста, скептики;

5. консерваторы - 16\%. [2, с.122]

Существенным шагом в достижении повышения эффективности туристической отрасли является учет интересов всех этих групп. Именно исследование рынка потребителей, выявление их наклонностей и предпочтений, далее предложение новых туристических услуг задача идущих в ногу со временем туристических агентств [3, раздел 3.1.].

Таблица 8. Маркетинговые стратегии для туристических услуг в Азербайджане

\begin{tabular}{|c|c|}
\hline & \\
\hline $\begin{array}{l}\text { Р Разработка совершенно новых } \\
\text { турпакетов, которая требует значительных } \\
\text { затрат как по разработке, так и по по } \\
\text { продвижению их на старых и новых рынках } \\
\text { (новые фестивали, выставка, реализация } \\
\text { товаров народного потребления, мастеров, } \\
\text { ремесленников, организация } \\
\text { маршрутов лечебных туров и т.д.); } \\
>\text { Разработка новых туристических услуг } \\
\text { международного уровня - национальные } \\
\text { спортивные состязания, театральные } \\
\text { выступления, средневековые деревни и т.д.); } \\
>\text { Разработка рекламной деятельности с } \\
\text { целью продвижения на международном } \\
\text { уровне новых турпакетов. }\end{array}$ & $\begin{array}{l}\text { Разнообразие сложившихся турпакетов; } \\
\text { Адаптация старых и еще эффективных } \\
\text { турпакетов для различных слоев } \\
\text { потребителей (для консерваторов, для } \\
\text { пожилых людей или для подростков); } \\
>\text { Комбинирование туристических услуг } \\
\text { для корпоративных покупателей или для } \\
\text { семейного отдыха; } \\
>\text { Увеличение ассортимента услуг: } \\
\text { разнообразие маршрутов в экотуризме, } \\
\text { кулинарном туризме и т.д.; } \\
>\text { Охват малоимущих в туристические } \\
\text { услуги - занижение цен для малоимущих } \\
\text { при одновременном повышении цен для } \\
\text { богатых. }\end{array}$ \\
\hline Map & \\
\hline $\begin{array}{l}\text { D Улучшение } \text { туристических услуг и } \\
\text { продвижение их на международный уровень; } \\
>\text { Разработка новых турпакетов } \\
\text { иностранцев с уля } \\
\text { мышления; } \\
>\text { Разработка старых туристических услуг }\end{array}$ & $\begin{array}{l}>\text { Отказ от турпакетов внутри страны, } \\
\text { если турагентство вышел на мировой } \\
\text { уровень; } \\
>\text { долговременное предложение пакетов } \\
\text { по экотурам и кулинарному туризму. }\end{array}$ \\
\hline
\end{tabular}

Источник: составлена автором на основе данных [1-3]

Предприятия национального туризма, как правило, применяют несколько стратегий одновременно при продвижении туристических продуктов [3, раздел 3.1.]. Казалось бы, при выборе ассортимента турпродуктов и при их формировании учитываются все преимущества, необходимые рыночные условия, требования к организации и управлению, дестабилизирующие факторы. Но на самом деле многие туристические агентства раз за разом делают одни и те же ошибки, к которым относятся:

$>$ Независимо от величины туристического предприятия все они занимаются и зарубежными поездками, и турпакетами внутри страны, что создает большие неудобства самим агентствам, так как они вынуждены специализироваться по всем направлениям. И это в свою очередь еще раз доказывает, что за последние 28 лет турагентства так и не смогли формировать свою маркетинговую стратегию и развиваются наобум;

Агентства время от времени отказываются от налаженных турпакетов, так как со временем эти турпакеты дешевеют в себестоимости и это не выгодно туроператорам;

$>$ Агентства каждые 3-4 года меняют направления, что привлекательно ля бывалого туриста, но очень затратно для потребителей из групп консервантов;

$>$ При большом ассортименте продуктов агентства активизируют весь портфель предложений (продуктов), но не все они внедряются; 
Агентства часто сталкиваются вопросами гарантий безопасности туристов. Сюда входят и безопасность самого туриста и членов его семьи, т.е. физическая безопасность, и также безопасность при конвертировании валют, а также безопасность при использовании банковских карт. Естественно, в Азербайджане отсутствует некоторые банковские карты, которые дают путешественникам льготы при оплате проживания и питания в ресторанах, при покупке товаров [2, с.123].

Решение этих проблемы требует долгосрочной, комплексной и системной работы. Точно такой же работы требует обеспечение современным оборудованием для сбора и утилизации бытовых отходов и систем канализации подавляющего большинства туристических центров республики в регионах.

Основные стратегические приоритеты развития туризма в Азербайджане опираются на:

$>$ развитие новых направлений деятельности;

$>$ освоение новых типов турпродуктов;

$>$ завоевание новых рынков сбыта.

И в связи с этим Азербайджанским турагентствам необходимо освоить ряд маркетинговых стратегий с целью совершенствования их деятельности, инновационного развития и укрепления своих позиций на мировых рынках предложения туристических услуг.

Автор предлагает использовать SWOT матрицу для составления маркетинговых стратегий. Любой из выбранных приоритетов развития туризма требует анализа ресурсного потенциала районов и предприятий туризма (Под туристскими ресурсами понимают совокупность природных и созданных объектов, пригодных для создания турпродукта).

По результатам анализа районы и объекты туризма Азербайджана могут ранжироваться, например, по наличию условий для организации туристско-экскурсионного обслуживания, по состоянию предприятий туризма для включения в уже существующие туры и др.

На основе полученных результатов можно определить основные средства и методы стимулирования продвижения туристских продуктов. Для этого необходимо:

$>$ учитывать мотивы и потребности потенциальных клиентов;

$>$ барьеры к потреблению туристских услуг;

$>$ сегментацию и позиционирование рынка туристских услуг.

Выводы. На основе результатов сегментации необходимо определить:

$>$ Результаты SWOT анализа свидетельствуют о необходимости повышения эффективности использования ресурсного потенциала;

$>$ при аудите места нахождения туристского ресурса, его основных характеристик и функционального назначения, существенную (для эффективного управления) роль играет предельно допустимая нагрузка на объект, исходя из его состояния, размеров и других технических характеристик, источники его финансирования, доходность;

$>$ Сбор, обработка и систематизация сведений о туристских ресурсах требует формирования особого реестра туристских ресурсов;

$>$ Для эффективности туристических услуг необходимо улучшить информационное обеспечение турагентств;

$>\mathrm{C}$ целью совершенствования управления туристскими ресурсами необходимо усиление контроля над использованием туристических ресурсов, определение предельно допустимых нагрузок;

$>$ Для создания перспективных целевых рынков продвижения туристских продуктов необходимо учесть их риски, наличие конкурентов и их поведение.

\section{ЛИТЕРАТУРА}

1. Абасова С. Г. механизмы государственного регулирования внешнеэкономических инновационных процессов в развивающихся странах (на примере внешнеэкономических связей Азербайджана с другими странами). Новосибирск: изд-во ЦРНС, 2015, 234с.

2. Абасова С. Г., Дадашева А. М. Особенности процесса внедрения инноваций в туристических предприятиях. Материалы 4-го научно-практического семинара «Внедрение новых информационных технологий к информационному обеспечению НИОКР». Баку, Центр Научных инноваций при Президиуме НАН Азербайджана, 15 мая 2009г., с.117-126.

3. Александрова А. Ю. Международный туризм. М.: 2002, 337c. tourlib.net/books_tourism/aleks.htm; http://tourlib.net/books_tourism/aleks31.htm

4. Портер М. Конкурентная стратегия. Методика анализа отраслей конкурентов. М.: изд-во Альпина Паблишер, 2011, 454c.

5. Статистические показатели Азербайджана. www.stat.gov.org

6. Электронный ресурc: https://www.stat.gov.az/source/tourism

7. Электронный ресурc: https:/www.stat.gov.az/source/healthcare/ 